\title{
Thermographic analysis of the quality of wire connections with overcurrent switches
}

\author{
Daniel Tokarski ${ }^{1, *}$, Tomasz Grudniewski ${ }^{1}$, Marta Chodyka $^{1}$, Jerzy Antoni Nitychoruk $^{1}$ \\ ${ }^{1}$ Faculty of Economic and Technical Sciences, Pope John Paul II State School of Higher Education \\ in Biała Podlaska, Poland
}

\begin{abstract}
The article aims to present the issue of excessive heat release at installation joints due to insufficient contact surface of the joining elements. The conducted research attempts to estimate the losses caused by an insufficient contact surface area. A laser pyrometer and a thermal imaging camera were used to perform the tests. Both devices generate images without having to touch the tested element, which may indicate that the obtained results are very accurate. The completed tests have shown that an insufficient contact surface of the joints results in an increased heat release, which leads to higher electrical energy losses and increased wear of the installation connectors.
\end{abstract}

\section{Introduction}

The conducted research was aimed at investigating the relationship between the contact surface of joints and the heat released by these devices. The heat release on energy devices is an undesirable phenomenon, as it often means power losses in the transmission of electricity. Three independent electrical circuits were created for the tests. Each of them consisted of a $3 \times 2.5 \mathrm{~mm}^{2}$ cable, an overcurrent switch and a weight in the form of an electric motor of $5 \mathrm{KW}$. The only difference was the size of the contact of particular wires with overcurrent breakers. In the first circumference, the contact surface was the smallest, i.e. of $5 \mathrm{~mm}$. In the next circuit, the contact size was $10 \mathrm{~mm}$, and in the last one, it was $15 \mathrm{~mm}$. All three circuits were placed in a specially designed distribution box.

In addition to the tested items, there are also other elements in the box that facilitated the tests, but they were not the object of research. The tests were carried out at an ambient temperature of $16^{\circ} \mathrm{C}$. The devices used during the investigation were FLIR T420bx thermal imaging camera and Bestone BE900 laser pyrometer. Both instruments allow for noncontact measurement and do not take heat from the tested element, which is the case with touch devices attached to the tested elements. A thermal imaging camera is an optoelectronic device that analyses infrared temperature. However, cameras with the highest detection and thermal resolution parameters still use cryogenic matrices. Special hopes are placed on infrared multispectral imaging and the combination of thermal cameras with cameras and sensors of other types. The list of applications of thermal cameras in

* Corresponding author: $\underline{\text { d.tokarski@pswbp.pl }}$ 
civilian life includes over 100 and is constantly being expanded. The popularity of this type of camera is linked to its applications [6]:

- in communication - extending the range of view and detection of obstacles,

- in industrial diagnostics - individual equipment and image sensor networks,

- in robotics - military or civil machines,

- in fire and rescue service - working in conditions of limited visibility.

In contrast, laser pyrometers are an excellent alternative to traditional temperature meters, because a touch point on the tested element to measure temperature is not needed. Due to this, there is no need to approach the tested object. Such a solution is a safer and more hygienic than measuring the element with an ordinary thermometer [5].

Table 1. Basic parameters of the tested circuit breakers.

\begin{tabular}{|l|c|}
\hline Name of the parameter & Value \\
\hline Type of characteristic & $\mathrm{C}$ \\
\hline Number of phases & 3 \\
\hline Rated voltage 400V & $400 \mathrm{~V}$ \\
\hline Rated current & $20 \mathrm{~A}$ \\
\hline Rail mounting type & DIN \\
\hline Manual 'turn off' mode & YES \\
\hline
\end{tabular}

The selected switches have been working in an industrial plant for a year and are used on a regular basis. This ensures that they operate in identical installations, so that they can be subjected to a comparative analysis. Circuit breakers of this type are also used in home installations. The test results will allow for estimating the cost of incorrect or incompetent installation.

Currently, flat plate breakers mounted on a DIN TH35 bracket are used in electrical installations, with a standard width of $17.7 \mathrm{~mm}$ (per pole) for regular versions, and $27 \mathrm{~mm}$ (1.5 modules) for industrial versions (rated current up to $200 \mathrm{~A}$ and short-circuit currents up to $25 \mathrm{kA}$ ) [1]. They occur in 1, 2, 3 and 4-pole varieties. In addition, we distinguish variations of circuit breakers with a neutral track (e.g. 1P $+\mathrm{N}$ - single pole neutral) or without (e.g. 1P - unipolar without a neutral value). All circuit breakers were of the same class and had identical parameters, as shown in Table 1. Besides, all switches had identical electromagnetic releases and a manual 'on' or 'off' switch mode in the form of a manual lever located on the front of the device [3].

\section{Description of the conducted research}

The tests were carried out in several stages. The first stage involved preparing all circuits and contact surfaces, then switching on the weight and finally monitoring the contact temperature. Then, images were taken using a thermal imaging camera and analysed for heat transfer. The key step turned out to be the calculation of power losses caused by too small contact surface. The analysis of the conducted activities will provide a full view of the application of the appropriate contact surface, not only in typical industrial installations but also those in homes. As a result of the reduction of losses, energy consumption will also decrease, translating directly into savings, which is especially important in the case of industrial installations, where the amount of absorbed power is the highest. 


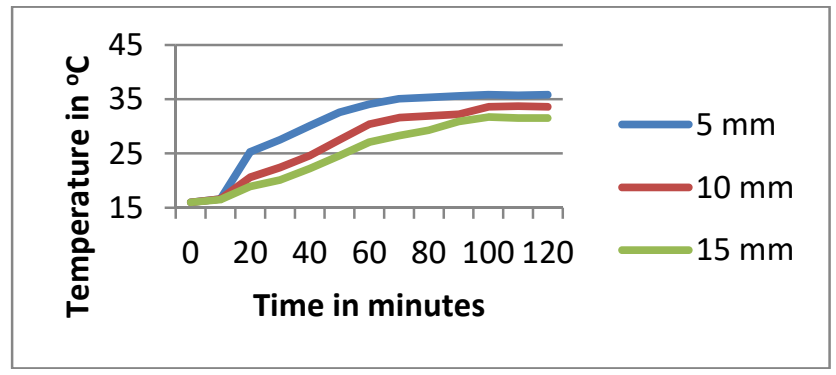

Fig. 1. Temperature change with regard to the contact surface.

During the first stage, measurements were made at 10-minute intervals using the Bestone BE900 laser pyrometer. The surface of the joining surface affects not only the amount of the emitted heat but also how fast heat is generated at the contact points. It was noticed that the joints with the smallest contact surface heat up much faster than other places, the joint reaches the desired temperature after about 60 minutes, while in the other two cases the assumed temperature is achieved only after 1.5 hours. The measured differences oscillate between $5-30^{\circ} \mathrm{C}$, whereas in industrial conditions, where machines often work non-stop, the difference can be very significant (possible device error is $\pm 3^{\circ} \mathrm{C}$, but this has no significant effect on the final result of the experiment). It can also be noted that insufficient contact area, which leads to faster heating, results in a substantial reduction of the durability of all devices of the circuit, but first of all causes a faster wear of the overcurrent switch, which is to protect the installation. Consequently, a worn-out device does not provide sufficient quality of protection. Thus, taking care of the right quality of connections seems essential not only for economic reasons. It allows for more proper operation of the overcurrent switch or other installation connectors used in installations.

Table 2. Results of the thermographic measurement presented in Fig. 2.

\begin{tabular}{|c|c|c|c|}
\hline Thermogram & \multicolumn{2}{|c|}{ Measurements } & ${ }^{0} \mathrm{C}$ \\
\hline \multirow{9}{*}{1} & Li1 & Max & 36,7 \\
\hline & & Min & 34,1 \\
\hline & & Average & 36,2 \\
\hline & Li2 & Max & 35,2 \\
\hline & & Min & 33,0 \\
\hline & & Average & 33,7 \\
\hline & Li3 & Max & 32,3 \\
\hline & & Min & 30,9 \\
\hline & & Average & 32,0 \\
\hline \multirow{3}{*}{2} & & Sp1 & 35.8 \\
\hline & & $\mathrm{Sp} 2$ & 33.6 \\
\hline & & Sp3 & 31.7 \\
\hline \multirow{6}{*}{3} & & $\mathrm{Sp} 1$ & 36.8 \\
\hline & & Sp2 & 35.4 \\
\hline & & Sp3 & 32.6 \\
\hline & & Sp4 & 33.0 \\
\hline & & Sp5 & 33.4 \\
\hline & & Sp6 & 32.6 \\
\hline
\end{tabular}


Two hours later, when the contact temperature stabilised (stopped rising), images of the entire switchgear were taken using a thermal imaging camera. The obtained thermograms allowed for observing extremely hot places.

The first applied method used to analyse the thermograms is the linear analysis method. This analysis consists in marking the line in the picture (in this case the line of contacts), the programme analyses the temperature of the points on the line and finds the ones with the lowest and highest temperature to determine the average temperature of the points on the line. The mean value is counted from all the points on the line not only from the two extreme ones. Figure 2 shows uneven heating of the circuit breakers. The linear measurements of the temperature on the input connector of the overcurrent breakers (table 2) allowed for determining the average temperature of the connectors and estimating the average temperature differences between the three switches. The mean difference between the temperature at the first and third circuit breakers was $4.2^{\circ} \mathrm{C}$. In the case of multi-hour current flow; this can be a significant difference in the loss of the transmitted current [2]. It is also worth noting that for an ambient temperature of approx. $22^{\circ} \mathrm{C}$, the difference in the heating of the circuit breakers is probably even higher, and the individual circuit breakers could warm up to a much higher temperature. The difference in temperature is noticeable not only in successive switches but also between adjacent contacts of the same circuit breaker, which was due to the thermogram analysis by a computer programme. In fact, the temperature measured at the following contact points using the pyrometer results in the same findings.

a)

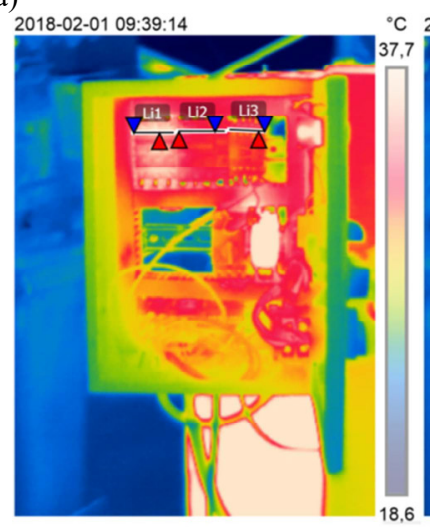

b)

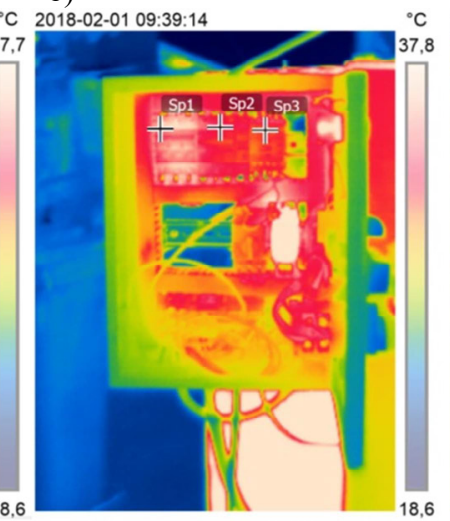

c)

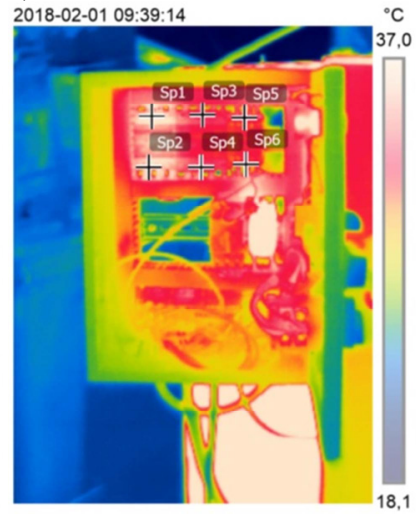

Fig. 2. a) Thermostat for the switchgear, b) linear analysis method, c) analysis of contact temperature differences.

Another method in the thermogram analysis is the point analysis, which consists in selecting points whose temperature is measured by the thermovision camera software. During this analysis, three points that represent the temperature of the contact connections of the subsequent overcurrent circuit breakers were selected to be the test objects. Comparing the average contact temperature was done using the linear analysis, as well as the point analysis method (Table 2), and, as noted, they were similar to each other. When compared to the measurements at points shown in Fig. 2., some differences in the contact temperature of the next three overcurrent circuit breakers were noticed. These differrences were comparable to ones obtained by the linear analysis. The similarity of the results obtained with two methods indicates that there is a relationship between the size of the connection joint and the temperature to which the breaker heats up. It is also clearly visible that, along with the connection points, the entire internal mechanisms of the overcurrent 
switches heat up. Thus, it might be deduced that the temperature inside the circuit breakers increases along with the temperature of the contacts. Such heating is dangerous because the circuit breaker consists of many small components that can easily get overheated and damaged. In this case, the switch may be damaged and, in the worst case, the user might not even realize that they no longer have overcurrent protection, which also has its consequences. By ensuring the right contact size, one may minimise both overheating and the likely damage to the installation connectors.

The last aspect of the conducted measurements was to estimate the temperature difference between the input and output contacts of the same overcurrent circuit breakers. To do that, the method of point analysis of the thermographic image was applied again, this time with six selected measuring points. The contact surface of the output connections was identical to the contact surfaces of the input connections. The temperature difference between the input and output contacts was not large but noticeable and amounted to approximately $1^{\circ} \mathrm{C}$. Such a small difference is caused primarily by the mechanical construction of the overcurrent breaker and the arrangement of the elements inside the device case. In the case of the first and third circuit breakers, the triggers and electromagnetic coils are located close to the upper contacts, so that the upper contacts of these circuit breakers heat up more strongly. However, the second switch has a slightly different structure, and the triggers and the coil are located close to the bottom contacts. This arrangement caused slightly greater heating of the lower contacts - the output ones.

Having conducted the analysis, we found that not all joints with identical contact surface heat evenly. Temperatures of the contacts are also influenced by other factors such as the mechanical construction of the above-mentioned circuit breaker, contamination of the contact location, fluctuation of network voltages, and first of all voltage spikes and other factors. However, in the case of the tested joints, the contact surface turned out to be a crucial factor. As for the temperature level of the lower and upper contacts, the temperature difference was small and amounted to $1.4^{\circ} \mathrm{C}$ for the contact surface of $5 \mathrm{~mm}, 0.4^{\circ} \mathrm{C}$ for the contact surface of $10 \mathrm{~mm}$, and $0.8^{\circ} \mathrm{C}$ for the contact surface of $15 \mathrm{~mm}$. In addition, it was found that the temperature of the upper and lower contacts of the circuit breakers with a contact area of $10 \mathrm{~mm}$ and $15 \mathrm{~mm}$ was similar, which proves that with a given area of $10 \mathrm{~mm}$, the contact surface is sufficient to prevent uneven heating of switching points of overcurrent switches.

\section{Conclusions}

The multistage tests carried out with the use of a thermal imaging camera and a laser pyrometer allow for stating explicitly that the contact surface of the joint has a direct impact on the temperature of the connection itself as well as all wires and devices in the vicinity. Joints with a larger contact surface show a lower tendency to heat both the connection point itself and the entire overcurrent circuit breaker. Insufficient contact surface in almost all cases is caused by the carelessness of the person who did the joining. Therefore, the conclusion might be that more considerate attention should be paid when the joining is done as it may not only reduce the heat release at the joining surface, which will reduce power losses, but also allow for proper maintaining the network connectors, which in turn will ensure users reliable operation of all installation protections. As proven by the test described in the article, increasing the contact area from $5 \mathrm{~mm}$ to $15 \mathrm{~mm}$ will allow for a temperature reduction of approx. $4^{\circ} \mathrm{C}$. A smaller amount of the generated heat means fewer electricity losses and, consequently, lower electricity bills. It can be noted, therefore, that a low work expense can reduce some of the losses and improve the efficiency of the entire electrical network of the company or home. 


\section{References}

1. M. Doległo, (Podstawy elektrotechniki i elektroniki, Wydawnictwa Komunikacji i Łączności WKŁ, 2016)

2. S. Bolkowski, (Teoria obwodów elektrycznych, Wydawnictwo Naukowe PWN, Warszawa, 2018)

3. L. Grzesiak, A. Kaszewski, B. Ufnalski, (Sterowanie napędów elektrycznych, Wydawnictwo Naukowe PWN, Warszawa, 2016)

4. A. Chwaleba, M. Poniński, A. Siedlecki, (Metrologia elektryczna, WNT, Warszawa, 2014)

5. J. Kowalczyk, W. Głocki, (Podstawy elektroniki, Difin, Warszawa, 2015)

6. D. Tokarski, B. Zegardło, P. Ogrodnik, P. Woliński, G. Adamczewski, (Analiza możliwości zastosowania nowoczesnej aparatury elektrotechnicznej w postaci kamery termowizyjnej do wykrywania mikro mostków cieplnych $w$ budynku przy zastosowaniu termografii, Wiadomości elektrotechniczne, Wyd. Czasopism i Książek Technicznych SIGMA-NOT, 08, 2017)

7. E. Krawczak, S. Gułkowski, E3S Web of Conferences 19, 03011 DOI: 10.1051/ e3sconf/20171903011 (2017) 